\title{
EarthArXiv: Today and Tomorrow
}

\author{
TOM NAROCK ${ }^{1}$, ROCHELLE TAYLOR ${ }^{2}$, EVAN \\ GOLDSTEIN $^{3}$, ARTHUR BOSTON ${ }^{4}$ AND DASAPTA ERWIN \\ IRAWAN $^{5}$ \\ ${ }^{1}$ Goucher College \\ ${ }^{2}$ Edge Hill University \\ ${ }^{3}$ University of North Carolina at Greensboro \\ ${ }^{4}$ Murray State University \\ ${ }^{5}$ Institut Teknologi Bandung \\ Presenting Author: thomas.narock@goucher.edu
}

EarthArXiv is a preprint service for the Earth sciences - a web-based system that enables open access publishing of non peer-reviewed scholarly manuscripts before publication in a peer-reviewed journal. In this presentation, we provide analytics on the usage of EarthArXiv across a number of sub-disciplines of Earth science. Data indicate that the service in general is growing, but with submission rates varying amongst discipline. The trend of the preprint-to-postprint ratio for each discipline also provides insight into how the various Earth science communities are using the service. We investigate were preprints are published after submission to EarthArXiv and examine how many of these publication venues are listed in the Directory of Open Access Journals. Finally, we will discuss future opportunities we are exploring to make preprints more accepted and easier to use. 